\title{
Effects of methimazole on the elimination of irinotecan
}

\author{
Jessica M. van der Bol • Theo J. Visser • Walter J. Loos • Floris A. de Jong • \\ Erik A. C. Wiemer • Maarten O. van Aken • Andre S. Planting • Jan H. Schellens • \\ Jaap Verweij · Ron H. J. Mathijssen
}

Received: 27 April 2010 / Accepted: 16 July 2010 / Published online: 1 August 2010

(C) The Author(s) 2010. This article is published with open access at Springerlink.com

\begin{abstract}
Purpose To study the possible pharmacokinetic and pharmacodynamic interactions between irinotecan and methimazole.

Methods A patient treated for colorectal cancer with single agent irinotecan received methimazole co-medication for Graves' disease. Irinotecan pharmacokinetics and side effects were followed during a total of four courses (two courses with and two courses without methimazole).

Results Plasma concentrations of the active irinotecan metabolite $\mathrm{SN}-38$ and its inactive metabolite SN-38Glucuronide were both higher (a mean increase of 14 and $67 \%$, respectively) with methimazole co-medication, compared to irinotecan monotherapy. As a result, the mean $\mathrm{SN}-38$ glucuronidation rate increased with $47 \%$ during concurrent treatment. Other possible confounding factors
\end{abstract}

J. M. van der Bol · W. J. Loos · F. A. de Jong · E. A. C. Wiemer ·

A. S. Planting $\cdot$ J. Verweij $\cdot$ R. H. J. Mathijssen $(\bowtie)$

Department of Medical Oncology,

Erasmus MC University Hospital, Daniel den Hoed

Cancer Center, 's Gravendijkwal 230,

3015 CE Rotterdam, The Netherlands

e-mail: a.mathijssen@erasmusmc.nl

T. J. Visser · M. O. van Aken

Department of Endocrinology, Erasmus MC,

Rotterdam, The Netherlands

J. H. Schellens

Division of Clinical Pharmacology,

Netherlands Cancer Institute-Antoni

van Leeuwenhoek Hospital, Amsterdam, The Netherlands

J. H. Schellens

Science Faculty, Department of Pharmaceutical Sciences,

Utrecht University, Utrecht, The Netherlands did not change over time. Specific adverse events due to methimazole co-treatment were not seen.

Conclusions Additional in vitro experiments suggest that these results can be explained by induction of UGT1A1 by methimazole, leading to higher SN-38G concentrations. The prescribed combination of these drugs may lead to highly toxic intestinal SN-38 levels. We therefore advise physicians to be very careful in combining methimazole with regular irinotecan doses, especially in patients who are prone to irinotecan toxicity.

Keywords Irinotecan - Methimazole - Drug interaction . UGT1A $\cdot$ Diarrhea $\cdot \mathrm{SN}-38 \cdot \mathrm{CYP} 3 \mathrm{~A}$

$\begin{array}{ll}\begin{array}{l}\text { Abbreviations } \\ \text { APC }\end{array} & \begin{array}{l}\text { 7-Ethyl-10-[4- } N \text {-(5-aminopentanoic acid)- } \\ \text { 1-piperidino]-carbonyloxy-camptothecin }\end{array} \\ \text { CES } & \begin{array}{l}\text { Carboxylesterases } \\ \text { CYP3A }\end{array} \\ \text { Cytochrome P450 3A isoforms } \\ \text { NPC } & \begin{array}{l}\text { 7-Ethyl-10-[4-amino-1-piperidino]-carbonyl- } \\ \text { oxycamptothecin }\end{array} \\ \text { SN-38 } & \text { 7-Ethyl-10-hydroxy camptothecin } \\ \text { SN-38G } & \begin{array}{l}\text { Glucuronide form of SN-38 } \\ \text { UGT1A }\end{array} \\ & \begin{array}{l}\text { Uridine diphosphate glucuronosyltransferase } \\ \text { 1A isoforms }\end{array}\end{array}$

\section{Introduction}

Irinotecan is extensively used in the treatment of advanced colorectal cancer [1]. It is a pro-drug of the active compound $\mathrm{SN}-38$ and is metabolized by cytochrome $\mathrm{P} 450$ 3A (CYP3A) into inactive metabolites (Fig. 1a). In the liver, uridine diphosphate glucuronosyltransferase 1A (UGT1A) is capable of inactivating $\mathrm{SN}-38$ to its glucuronide form 
Fig. 1 Pharmacokinetics of irinotecan and metabolites. a Irinotecan is converted into its 1,000 times more active metabolite $S N-38$ by carboxylesterases $(C E S)$, which are predominately found in the liver. The affinity for this reaction is low, since only a fraction of irinotecan is directly converted into $S N-38$. Competing with the formation of $S N-38$ is the CYP3A-mediated inactivation of irinotecan into the metabolites $A P C$ and NPC. In turn, carboxylesterases also have the ability to convert both of these compounds into $S N-38$. $S N-38$ is glucuronidated by UGT1A into its inactive metabolite $S N-38 G$. In the intestines, $\beta$-glucuronidase-producing bacteria can reverse this latter reaction, and thus reactivate $S N-38$, which causes the dose-limiting toxicity diarrhea. Area under the plasma concentration versus time curves for irinotecan (b), NPC (c), APC (d), $\mathrm{SN}-38(\mathbf{e})$, and $\mathrm{SN}-38 \mathrm{G}$

(f) during all four chemotherapy courses. The open and closed symbols describe the two courses with methimazole and the two courses without methimazole co-treatment, respectively
A

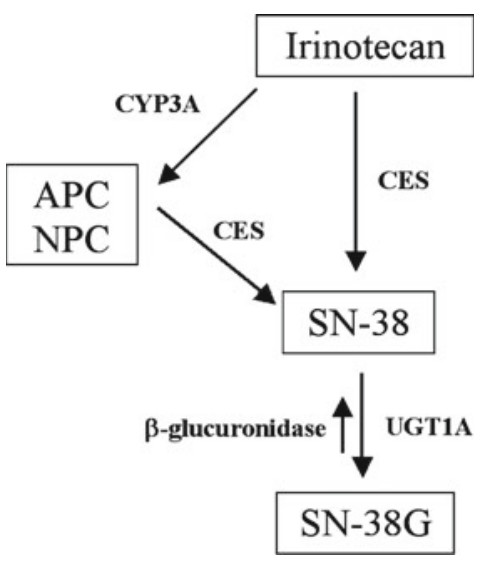

C

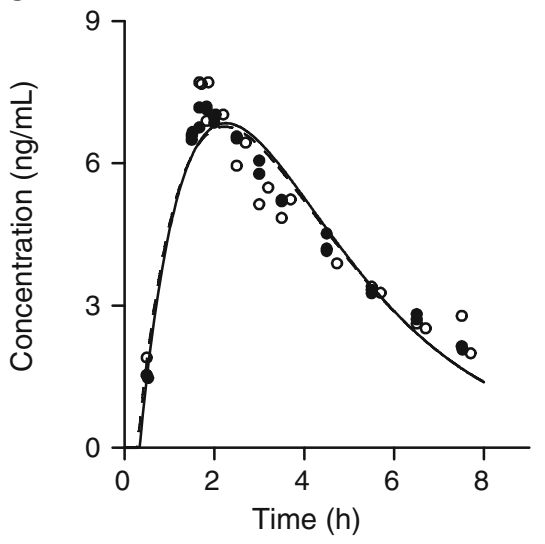

E

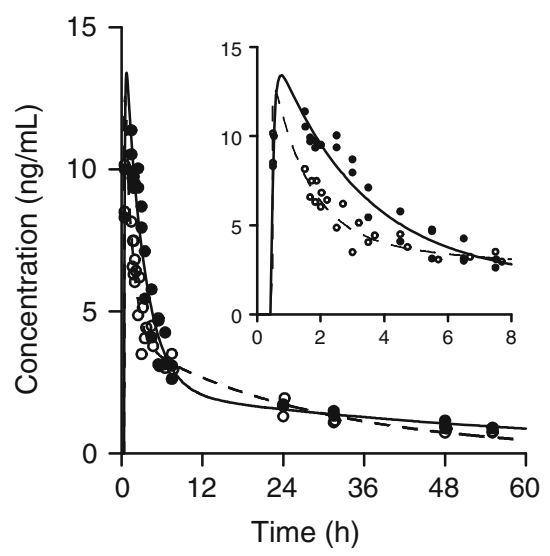

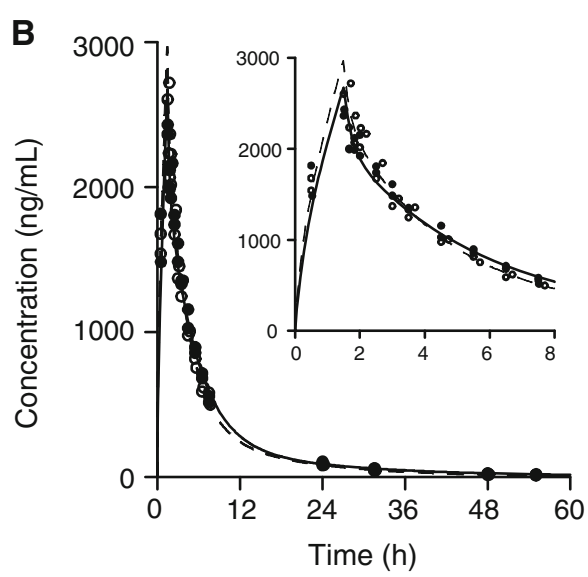

D

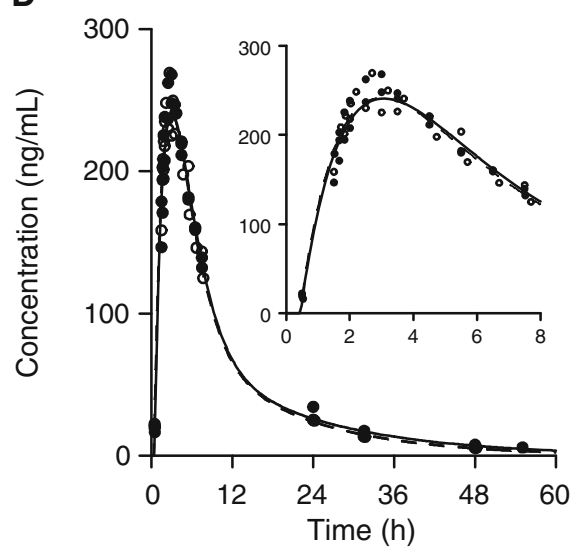

$\mathbf{F}$

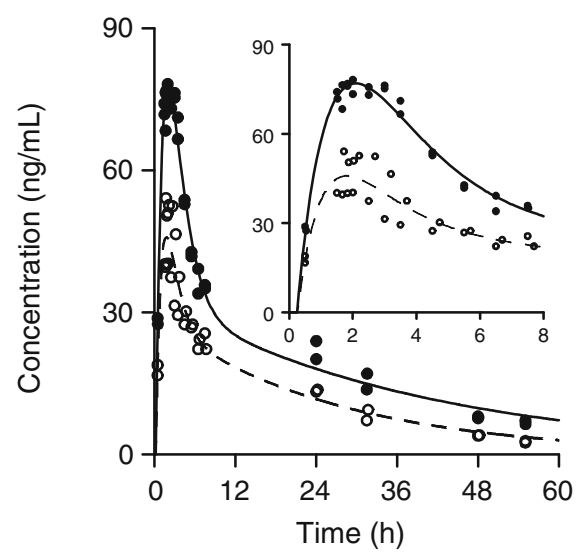

SN-38G, which facilitates excretion from the circulation [2]. In the intestines, SN-38G can be transformed back into SN-38 by bacterial $\beta$-glucuronidase. The metabolism of irinotecan is complicated by several drug-transporting proteins involved in the elimination of the drug (i.e. ATP-binding cassette transporters) [3]. Besides genetic alterations in the UGTIA gene, also environmental factors are known to influence its metabolism [3-5]. For instance, cigarette smoking may induce its metabolism, thereby decreasing the systemic exposure to $\mathrm{SN}-38$ [6].

Here, we report on a patient who used methimazole while being treated with irinotecan chemotherapy. We hypothesized that methimazole could seriously influence irinotecan metabolism, as pre-clinical data suggest that methimazole inhibits CYP3A [7] and induces certain UGT1A subtypes [8], both being crucial enzyme systems 
involved in the elimination of irinotecan and its metabolites. By performing additional in vitro experiments, we tested our hypothesis.

\section{Materials and methods}

Our patient was a cigarette smoking 53-year-old male, with locally advanced colorectal cancer. Six months prior to the start of irinotecan treatment, he was treated for hyperthyroidism due to Graves' disease using a combination of methimazole and levothyroxine. Other daily medicines were acetaminophen, fentanyl, pantoprazole, carbasalate calcium, metoclopramide, and dexamethasone. During two 3-weekly courses of irinotecan, the patient took a daily dose of $30 \mathrm{mg}$ methimazole. Two weeks after the second chemotherapy course, methimazole was stopped and the patient was treated with radioiodine (I-131) as a definitive treatment for Graves' hyperthyroidism. Without delay, the following courses of irinotecan were administered. After written informed consent, plasma pharmacokinetics of irinotecan and its metabolites were collected during a total of four courses. Patient-related factors (i.e. co-medication, smoking status), laboratory values and toxicities were closely monitored, $U G T 1 A 1 * 28$ genotype was determined, and active hormone 3,5,3'-triiodothyronine (T3), and thyroid stimulating hormone (TSH, thyrotropin) levels were determined to exclude possible confounding effects of varying thyroid status.

During and after the 90-min intravenous infusions of irinotecan $\left(350 \mathrm{mg} / \mathrm{m}^{2}\right)$, blood was drawn at specific timepoints [6]. Plasma concentrations of irinotecan, NPC, APC, SN-38, and SN-38G were determined using validated chromatography methods $[9,10]$. Individual plasma pharmacokinetics were estimated using non-compartmental analyses (WinNonLin 5.0, Pharsight, CA). At weekly outpatient visits, toxicities were scored.

Methods for the additional in vitro experiments are described in detail in the "Appendix" section.

\section{Results}

The area under the plasma concentration-time curve (AUC) of irinotecan did not differ between the courses with or without methimazole co-treatment (mean $16.1 \mu \mathrm{g} \times \mathrm{h} / \mathrm{mL}$; Fig. 1b; Table 1). However, plasma concentrations of both SN-38 and SN-38G were higher during the courses with methimazole (Fig. 1e, f). With methimazole, the mean SN38 AUC was $14 \%$ higher than without methimazole $(125 \mathrm{ng} \times \mathrm{h} / \mathrm{mL}$ vs. $110 \mathrm{ng} \times \mathrm{h} / \mathrm{mL})$. In the presence of methimazole, the mean SN-38G AUC was $67 \%$ higher $(1,255 \mathrm{ng} \times \mathrm{h} / \mathrm{mL}$ vs. $753 \mathrm{ng} \times \mathrm{h} / \mathrm{mL})$. Consequently, a
Table 1 Baseline characteristics, pharmacokinetics, chemistry, and toxicities during four treatment courses with irinotecan

\begin{tabular}{|c|c|c|c|c|}
\hline Irinotecan course & 1 & 2 & 3 & 4 \\
\hline Methimazole & Yes & Yes & No & No \\
\hline $\mathrm{TSH}(0.4-4.3 \mathrm{mU} / \mathrm{L})^{\mathrm{a}}$ & 0.0 & 2.6 & 0.0 & 0.0 \\
\hline T3 (1.4-2.5 nmol/L) & 1.54 & 2.11 & 2.14 & 2.86 \\
\hline Dose irinotecan (mg) & 660 & 660 & 660 & 660 \\
\hline $\operatorname{AUC}_{(0-56 \mathrm{~h})}$ irinotecan $(\mu \mathrm{g} \times \mathrm{h} / \mathrm{mL})$ & 16.6 & 16.0 & 15.8 & 16.0 \\
\hline $\mathrm{AUC}_{(0-56 \mathrm{~h})} \mathrm{APC}(\mathrm{ng} \times \mathrm{h} / \mathrm{mL})$ & 3,227 & 2,919 & 3,028 & 2,897 \\
\hline $\mathrm{AUC}_{(0-8 \mathrm{~h})} \mathrm{NPC}(\mathrm{ng} \times \mathrm{h} / \mathrm{mL})$ & 31.9 & 32.4 & 32.2 & 32.5 \\
\hline $\mathrm{AUC}_{(0-56 \mathrm{~h})} \mathrm{SN}-38(\mathrm{ng} \times \mathrm{h} / \mathrm{mL})$ & 117 & 133 & 106 & 114 \\
\hline $\mathrm{AUC}_{(0-56 \mathrm{~h})} \mathrm{SN}-38 \mathrm{G}(\mathrm{ng} \times \mathrm{h} / \mathrm{mL})$ & 1,301 & 1,209 & 728 & 777 \\
\hline REG & 11.1 & 9.09 & 6.87 & 6.82 \\
\hline Bilirubin (0-16 U/L) & 5 & 6 & 7 & 6 \\
\hline Alkaline phosphatase (0-119 U/L) & 189 & 182 & 176 & 152 \\
\hline$\gamma$-Glutamyltransferase (0-49 U/L) & 60 & 42 & 34 & 33 \\
\hline AST (0-36 U/L) & 20 & 21 & 18 & 16 \\
\hline ALT (0-40 U/L) & 24 & 23 & 24 & 18 \\
\hline Neutrophil nadir $\left(\times 10^{9} / \mathrm{L}\right)$ & 4.7 & 4.1 & 4.1 & 4.0 \\
\hline Diarrhea $(\text { grade })^{\mathrm{b}}$ & 1 & 0 & 0 & 0 \\
\hline
\end{tabular}

TSH Thyroid stimulating hormone, T3 active hormone 3,5,3' -triiodothyronine, $A U C$ area under the plasma concentration versus time curve, $S N-38$ active metabolite of irinotecan; $S N-38 G$ detoxified metabolite of SN-38, REG relative extent of glucuronidation, AST aspartate aminotransferase, $A L T$ alanine aminotransferase

a Normal values between brackets. For TSH and T3, means of weekly values within a period of 3 weeks have been given

b Grading according to National Cancer Institute-Common Terminology Criteria for Adverse Events version 3.0

mean $47 \%$ increased relative extent of glucuronidation, which is the ratio of $\mathrm{SN}-38 \mathrm{G}$ over SN-38 (mean, 10.1 vs. 6.85), was found during the combination treatment courses. The exposure to the CYP3A metabolites APC (mean $3,018 \mathrm{ng} \times \mathrm{h} / \mathrm{mL}$; Fig. 1d) and NPC (mean $32.3 \mathrm{ng} \times \mathrm{h} / \mathrm{mL}$; Fig. 1c) was not different between the courses with or without methimazole.

Except for methimazole, co-medication did not change during the studied courses and also smoking behavior of the patient (15-20 cigarettes per day) did not change. The patient appeared to be wild-type $\left(\mathrm{TA}_{6} / \mathrm{TA}_{6}\right)$ for $U G T 1 A 1 * 28$, meaning that UGT1A1 function was not lowered based on this familiar genetic polymorphism [3]. Thyroid hormone levels varied during the assessed courses (Table 1), with a transient but clear hyperthyroidism during the fourth course. Nevertheless, a correlation between thyroid function and systemic chemotherapy levels could not be established. Irinotecan-related toxicity was mild during all courses. The absolute neutrophil count nadir was similar in all courses (mean $4.2 \times 10^{9} / \mathrm{L}$ ).

In the in vitro experiments, simultaneous incubation of human liver microsomes with irinotecan and methimazole 
resulted in a slightly decreased formation of NPC and APC (both 16\% reduced compared to incubation in the absence of methimazole; Appendix Fig. 2a). Control experiments in which irinotecan was combined with fluconazole, a known potent CYP3A-inhibitor, resulted in a strong inhibition of NPC and APC formation (78 and 74\% inhibition, respectively, compared to experiments in the absence of fluconazole; Appendix Fig. 2a). No effect of methimazole on SN-38 formation was noticed. In addition, SN-38G formation did not decrease during the co-incubation of microsomes with methimazole and $\mathrm{SN}-38$, while a reduction of $43 \%$ was observed during simultaneous incubation of SN-38 with the UGT1A1 inhibitor ketoconazole.

In order to determine whether methimazole is capable of inducing UGT1A1 expression, a HCT 116 colorectal carcinoma cell-line was cultured in the presence of various concentrations of methimazole $(25-100 \mu \mathrm{M})$ for $\sim 48 \mathrm{~h}$ after which UGT1A1 mRNA levels were measured by quantitative RT-PCR. Appendix Fig. $2 b$ displays the results of the experiment showing a 15-18-fold induction of UGT1A1 mRNA levels by methimazole compared to untreated control cells. The lowest concentration of methimazole $(25 \mu \mathrm{M})$ gave rise to the highest induction levels after $48 \mathrm{~h}$, whereas the higher concentrations (50 and $100 \mu \mathrm{M})$ already showed strongly elevated UGT1A1 levels after $24 \mathrm{~h}$ that seem to return to normal in a concentration-dependent manner after a longer incubation period.

Our in vitro tests in which the transport of mitoxantrone by ABCG2 was studied showed that methimazole in concentrations up to $100 \mu \mathrm{M}$ did not affect the efflux of mitoxantrone. In contrast, the known ABCG2 inhibitor Ko-143 reduced the efflux of mitoxantrone, thereby causing accumulation of the drug.

\section{Discussion}

In the current case, factors known to significantly alter irinotecan pharmacokinetics did not change over time, except for the use of methimazole. As a relationship between thyroid status and plasma concentrations of chemotherapy was not found, a possible influence of thyroid hormone on UGT1A activity is probably very limited in our case [11]. Therefore, we assume that the intra-patient differences in pharmacokinetics found over the courses are mainly attributable to methimazole.

Irinotecan drug-concentrations assessed in the courses without methimazole are within the low-normal range of literature data $[6,12,13]$, possibly due to patients' smoking behavior. As SN-38 levels are only moderately increased, while SN-38G concentrations are much higher in the presence of methimazole, our clinical data support the preclinical literature describing combined effects of CYP3A- inhibition and UGT1A-induction by methimazole [7, 8]. However, inhibition of CYP3A was not confirmed by lower systemic concentrations of NPC and APC in the courses with methimazole. In addition, our in vitro experiments could not determine an important effect of methimazole on CYP3A activity. Therefore, we have to conclude that the involvement of CYP3A is probably limited in the observed pharmacokinetic alterations during methimazole exposed courses.

UGT1A induction in turn will lead to increased SN-38G levels, catalyzing SN-38 transformation into SN-38G. This is expressed by the higher glucuronidation rate during the combination treatment. Although the exact mechanism of irinotecan-induced delayed-onset diarrhea is unclear, there is consensus that intestinal toxicity is caused by local reactivation of $\mathrm{SN}-38$ from $\mathrm{SN}-38 \mathrm{G}$ by $\beta$-glucuronidase-producing bacteria in the gut $[14,15]$. Therefore, higher SN-38G levels as a result of methimazole co-treatment could potentially lead to more intestinal toxicity, since higher systemic $\mathrm{SN}-38 \mathrm{G}$ concentrations could cause increased intestinal SN-38 levels when SN-38G is excreted in the gut and is de-glucuronidated by intestinal bacteria. This was also shown in a population-pharmacokinetic model of irinotecan, in which the AUC of SN-38G was correlated with diarrhea scores $(P<0.005)$ [16]. In addition, it was shown that co-treatment with the antibiotic neomycin reduces the fecal $\beta$-glucuronidase activity and fecal $\mathrm{SN}-38 \mathrm{G} / \mathrm{SN}-38$ ratio, thereby reducing the incidence of diarrhea [17].

In our view, it is plausible that the effect of higher SN38G levels in our patient did not result in more diarrhea because this patient already had a low pharmacokinetic and toxicity profile, most likely because of his smoking behavior and wild-type $U G T I A I * 28$ genotype [6]. However, in patients who are more prone to toxicity, higher $\mathrm{SN}-38 \mathrm{G}$ levels as a result of concomitant methimazole use, could potentially lead to severe diarrhea.

One cannot formally rule out the possibility that additional mechanisms contribute to the observed clinical phenotype. For instance, methimazole might interfere with ABC-transporters involved in the efflux of the irinotecan metabolites, leading to accumulation of SN-38 and SN$38 \mathrm{G}$. However, there is no literature available indicating that methimazole is a substrate or inhibitor of ABC-transporters. Moreover, our experiments confirmed that therapeutic concentrations of methimazole do not affect ABCG2-mediated transport.

\section{Conclusions}

Although the exact explanation for our findings is subject for further study, the combination of irinotecan and methimazole might potentially lead to increased toxicity 
due to higher systemic SN-38 and SN-38G concentrations. Reactivation of high concentrations SN-38G by bacterial enzymes in the bowel is potentially dangerous in that respect and could lead to local toxicity. We therefore advise physicians to be careful in combining methimazole with regular irinotecan doses, especially in patients who are prone to irinotecan toxicity.

Acknowledgments We thank P. de Bruijn, P. van Kuijk, and A. W. M. Boersma for performing in vitro experiments and analytical measurements.

Conflicts of interest We have no conflicts of interest or disclosures. There was also no financial support to perform the in vitro experiments.

Open Access This article is distributed under the terms of the Creative Commons Attribution Noncommercial License which permits any noncommercial use, distribution, and reproduction in any medium, provided the original author(s) and source are credited.

\section{Appendix}

Methods of in vitro experiments

In vitro experiments were performed to study the effects of methimazole on the metabolism of irinotecan and SN-38. Pooled human liver microsomes were incubated for $30 \mathrm{~min}$ with irinotecan $(10 \mu \mathrm{M})$ in the presence or absence of methimazole $(37.5 \mu \mathrm{M})$ or fluconazole $(25 \mu \mathrm{M}$; CYP3A inhibitor) based on the method described by Slatter et al. [18]. The experiment was performed on 4 separate occasions. In each experiment, microsomal proteins $(1 \mathrm{mg} / \mathrm{mL})$ were incubated in triplicate. In addition, pooled human liver microsomes were incubated for 30 min with SN-38 $(5 \mu \mathrm{M})$ in the presence or absence of methimazole $(37.5 \mu \mathrm{M})$ or ketoconazole $(25 \mu \mathrm{M}$; UGT1A inhibitor) based on the method described by Yong et al. [19]. This experiment was performed on separate occasions, during which microsomal proteins $(0.8 \mathrm{mg} / \mathrm{mL})$ were incubated in triplicate. Experiments were terminated by the addition of a perchloric acid/ methanol solution. Irinotecan and metabolite concentrations from these experiments were measured, using the methods mentioned earlier (Fig. 2).

HCT116 colorectal carcinoma cells were cultured in Glutamax ${ }^{\mathrm{TM}}$ containing Hepes-buffered RPMI 1640 medium supplemented with $10 \%$ fetal calf serum (Gibco BRL, Paisley, UK), $100 \mathrm{U} / \mathrm{mL}$ penicillin and $100 \mu \mathrm{g} / \mathrm{mL}$ streptomycin at $37^{\circ} \mathrm{C}$ in a humidified atmosphere containing $5 \% \mathrm{CO}_{2}$. HCT 116 cultures of $60 \%$ confluence were cultured in the presence of methimazole $(25,50$, and $100 \mu \mathrm{M})$ or $0.1 \%(\mathrm{v} / \mathrm{v}) \mathrm{MeOH}$ as a solute control. After 5, 24 or $48 \mathrm{~h}$, total RNA was extracted using RNA-Bee (Tel-TEST Temco, Inc. Friendswood, TX). Relative UGT1A1 mRNA
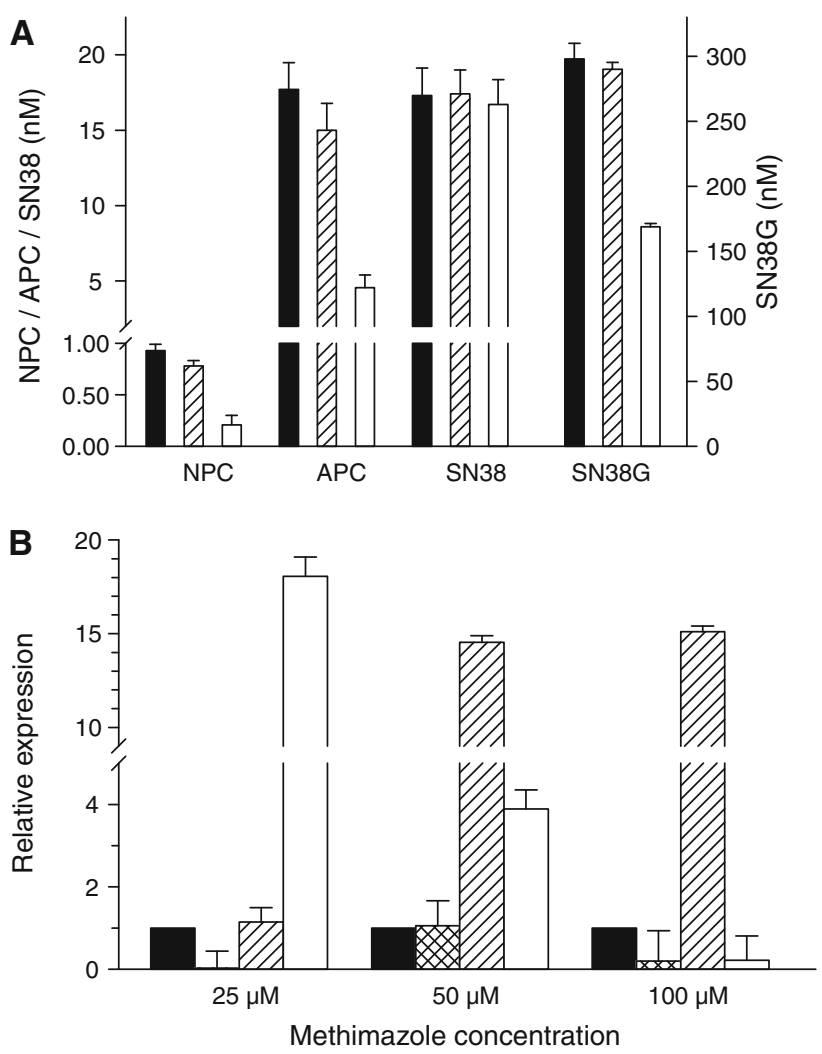

Fig. 2 In vitro experiments. a Effects of methimazole (striped bars) and fluconazole (open bars) on the formation of $N P C, A P C$, and $S N-38$ during co-incubation with irinotecan, and effects of methimazole (striped bars) and ketoconazole (open bars) on the formation of $S N 38 G$ during co-incubation with $S N-38$. The black bars represent the formation of irinotecan metabolites in the absence of any (potential) inhibitor. b Methimazole induces UGT1A1 mRNA levels. HCT116 cells were cultured in the presence or absence (control) of various concentrations of methimazole. At 5 (cross-hatched bar), 24 (hatched bar) and 48 (white bar) hours total RNA was isolated and used to measure UGT1A1 mRNA levels by quantitative RT-PCR (Taqman ${ }^{\mathrm{TM}}$ ). Depicted is the expression of UGT1A1 compared to the control UGT1A1 levels (black bar), which are arbitrarily set at 1. Error bars indicate $2 \times$ standard deviation $(n=3)$

expression levels were measured by real-time RT-PCR using the Taqman Universal Master mix and Assay-OnDemand products from Applied Biosystems (UGT1A1 assay ID: Hs02511055-s1). The human glyceraldehyde-3phosphate dehydrogenase (GAPDH assay ID: 4310884E; VIC/TAMRA) was used for normalization. Reactions were run on an ABI PRISM 7900 sequence detector system (Applied Biosystems, Foster City, CA) using the following cycling conditions: $50^{\circ} \mathrm{C}$ for $2 \mathrm{~min}, 95^{\circ} \mathrm{C}$ for $10 \mathrm{~min}$ followed by 40 cycles of $95^{\circ} \mathrm{C}$ for $15 \mathrm{~s}$, and $60^{\circ} \mathrm{C}$ for $1 \mathrm{~min}$.

Hek293 cells transfected with pcDNA3 (HEK293/neo) or wild-type BCRP/ABCG2-R482R (HEK293/R) were cultured under similar conditions as HCT116. To investigate whether ABCG2 activity is affected by methimazole, we analyzed the intracellular accumulation of mitoxantrone 
(a well known ABCG2 substrate) in the presence of methimazole. A cell suspension of $10^{6}$ cells of HEK293/neo or HEK293/R in RPMI1640 medium without further supplements was incubated in the presence of $3 \mu \mathrm{M}$ mitoxantrone at $37^{\circ} \mathrm{C}$ for $90 \mathrm{~min}$ with or without the addition of 10,25 , $50,100 \mu \mathrm{M}$ methimazole or $200 \mathrm{nM}$ of the fumitremorgin $\mathrm{C}$ analog Ko-143. The mitoxantrone accumulation (fluorescence intensity) was determined by flow cytometry as described previously [20].

\section{References}

1. Vanhoefer U, Harstrick A, Achterrath W, Cao S, Seeber S, Rustum YM (2001) Irinotecan in the treatment of colorectal cancer: clinical overview. J Clin Oncol 19:1501-1518

2. Di Paolo A, Bocci G, Danesi R, Del Tacca M (2006) Clinical pharmacokinetics of irinotecan-based chemotherapy in colorectal cancer patients. Curr Clin Pharmacol 1:311-323

3. Innocenti F, Kroetz DL, Schuetz E, Dolan ME, Ramirez J, Relling M, Chen P, Das S, Rosner GL, Ratain MJ (2009) Comprehensive pharmacogenetic analysis of irinotecan neutropenia and pharmacokinetics. J Clin Oncol 27:2604-2614

4. de Jong FA, Sparreboom A, Verweij J, Mathijssen RH (2008) Lifestyle habits as a contributor to anti-cancer treatment failure. Eur J Cancer 44:374-382

5. Mathijssen RH, Verweij J, de Bruijn P, Loos WJ, Sparreboom A (2002) Effects of St. John's wort on irinotecan metabolism. J Natl Cancer Inst 94:1247-1249

6. van der Bol JM, Mathijssen RH, Loos WJ, Friberg LE, van Schaik RH, de Jonge MJ, Planting AS, Verweij J, Sparreboom A, de Jong FA (2007) Cigarette smoking and irinotecan treatment: pharmacokinetic interaction and effects on neutropenia. J Clin Oncol 25:2719-2726

7. Guo Z, Raeissi S, White RB, Stevens JC (1997) Orphenadrine and methimazole inhibit multiple cytochrome P450 enzymes in human liver microsomes. Drug Metab Dispos 25:390-393

8. Visser TJ, Kaptein E, Gijzel A, de Herder WW, Cannon ML, Bonthuis F, de Greef WJ (1996) Effects of thyroid status and thyrostatic drugs on hepatic glucuronidation of lodothyronines and other substrates in rats. Endocrine 4:78-85

9. de Bruijn P, Willems EW, Loos WJ, Verweij J, Sparreboom A (2004) Indirect determination of the irinotecan metabolite
7-ethyl-10-O-glucuronyl-camptothecin in human samples. Anal Biochem 328:84-86

10. Sparreboom A, de Bruijn P, de Jonge MJ, Loos WJ, Stoter G, Verweij J, Nooter K (1998) Liquid chromatographic determination of irinotecan and three major metabolites in human plasma, urine and feces. J Chromatogr B Biomed Sci Appl 712:225-235

11. Van Steenbergen W, Fevery J, De Vos R, Leyten R, Heirwegh KP, De Groote J (1989) Thyroid hormones and the hepatic handling of bilirubin. I. Effects of hypothyroidism and hyperthyroidism on the hepatic transport of bilirubin mono- and diconjugates in the Wistar rat. Hepatology 9:314-321

12. Kehrer DF, Mathijssen RH, Verweij J, de Bruijn P, Sparreboom A (2002) Modulation of irinotecan metabolism by ketoconazole. J Clin Oncol 20:3122-3129

13. Tobin PJ, Beale P, Noney L, Liddell S, Rivory LP, Clarke S (2006) A pilot study on the safety of combining chrysin, a non-absorbable inducer of UGT1A1, and irinotecan (CPT-11) to treat metastatic colorectal cancer. Cancer Chemother Pharmacol 57:309-316

14. Takasuna K, Hagiwara T, Hirohashi M, Kato M, Nomura M, Nagai E, Yokoi T, Kamataki T (1996) Involvement of beta-glucuronidase in intestinal microflora in the intestinal toxicity of the antitumor camptothecin derivative irinotecan hydrochloride (CPT-11) in rats. Cancer Res 56:3752-3757

15. Takasuna K, Hagiwara T, Hirohashi M, Kato M, Nomura M, Nagai E, Yokoi T, Kamataki T (1998) Inhibition of intestinal microflora beta-glucuronidase modifies the distribution of the active metabolite of the antitumor agent, irinotecan hydrochloride (CPT-11) in rats. Cancer Chemother Pharmacol 42:280-286

16. Xie R, Mathijssen RH, Sparreboom A, Verweij J, Karlsson MO (2002) Clinical pharmacokinetics of irinotecan and its metabolites in relation with diarrhea. Clin Pharmacol Ther 72:265-275

17. Kehrer DF, Sparreboom A, Verweij J, de Bruijn P, Nierop CA, van de Schraaf J, Ruijgrok EJ, de Jonge MJ (2001) Modulation of irinotecan-induced diarrhea by cotreatment with neomycin in cancer patients. Clin Cancer Res 7:1136-1141

18. Slatter JG, Su P, Sams JP, Schaaf LJ, Wienkers LC (1997) Bioactivation of the anticancer agent CPT-11 to SN-38 by human hepatic microsomal carboxylesterases and the in vitro assessment of potential drug interactions. Drug Metab Dispos 25:1157-1164

19. Yong WP, Ramirez J, Innocenti F, Ratain MJ (2005) Effects of ketoconazole on glucuronidation by UDP-glucuronosyltransferase enzymes. Clin Cancer Res 11:6699-6704

20. Burger H, van Tol H, Boersma AW, Brok M, Wiemer EA, Stoter G, Nooter K (2004) Imatinib mesylate (STI571) is a substrate for the breast cancer resistance protein (BCRP)/ABCG2 drug pump. Blood 104:2940-2942 